\title{
The chronicles of coronaviruses: the bronchitis, the hepatitis and the common cold
}

\author{
K. Lalchhandama \\ Department of Life Sciences, Pachhunga University College, Aizawl, India
}

\begin{abstract}
Coronaviruses first appeared as chicken virus that cause respiratory disease. Historical reconsideration tells that coronavirus infection originated in the early $20^{\text {th }}$ century. The first definitive account of the infection was given by Arthur Schalk and Merle Fawn in 1931 as a "new respiratory disease of baby chicks." Leland Bushnell and Carl Brandly established virus as the causative agent in 1933 and was called infectious bronchitis virus (IBV), which eventually became the coronavirus type species. An apparently unrelated viral infection was discovered from laboratory mice in 1949 as JHM that caused encephalomyelitis and another in 1951 as mouse hepatitis virus (MHV). Study in the 1960s of viruses causing common colds in humans revealed unusual human viruses (designated B814 and 229E as the sample codes). Development of transmission electron microscopy enabled structural visualisation for the first around time -and with startling revelation - IBV, MHV, B814 and 229E were fundamentally the same virus having characteristic halo around the spherical viral core, a reminisce of solar corona for which they get a new name, coronaviruses, in 1968. The available historical records are incomplete and sometimes inaccurately represented, and this article attempt to mend the flaws whilst giving a more detailed account.
\end{abstract}

Keywords: Coronavirus, common cold, infectious bronchitis virus, mouse hepatitis virus, respiratory disease

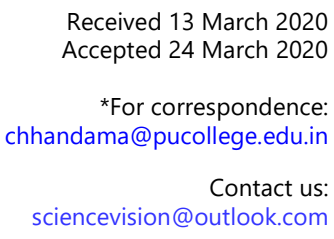

\section{Introduction}

Terror has a new name, and it has been christened coronavirus. With its enormous fame and global dominance, it may sound as a very distinct pathogen but is not alien to science as a group of 39 species. ${ }^{1}$ These are viruses of old, their infections of which were known a century ago. The eeriest part of their nature is that they turn up as a bad penny at odd times to bring about respiratory diseases (sometimes with anomalous symptoms such as pneumonia, enteritis, encephalitis, hepatitis, and common cold) in chickens, mice, pigs, and humans, among other mammals. ${ }^{2}$ SARS-CoV-2, with its pandemic infection COVID-19, is our latest guest among members of the family Coronaviridae, making itself quite at home in almost all the countries, and with a cataclysmic consequence on medical, political, and socio-economic conditions of the global community.

The concept of "global village", we experience, has a fatal downside after all. Our new keywords are 
pandemic, lockdown, quarantine, flatten the curve, and herd immunity; and social distancing, wearing mask, hand washing, sanitising, online education and stay at home are our new normal. We either underestimated the supremacy of natural selection or just did not care - either way, we pay a heavy price. And for evolution dissenters, they can stare at and contemplate over their religious establishment under total shutdown - if that do not make them think twice, nothing will.

Coronaviruses are classified into four genera, namely Alphacoronavirus, Betacoronavirus, Deltacoronavirus and Gammacoronavirus. They are the largest viruses in size and number in the order Nidovirales, which contains three families Coronaviridae, Arteriviridae and Roniviridae. The genus Alphacoronavirus includes viruses of camel, cat and pig; Betacoronavirus includes those of horse, mouse and cow; Deltacoronavirus includes those of bulbul and sparrow; and Gammacoronavirus chicken and whale. Human and bat coronaviruses fall under both Alphacoronavirus and Betacoronavirus. ${ }^{3}$

We have encountered these fascinating, while terrifying are some, coronaviruses since the early $20^{\text {th }}$ century. They were discovered as highly infectious and fatal respiratory pathogens in chicken. The array of hosts they infect and their types increased each decade, each of which is linked to emergence of respiratory disease of unique pathological difference. When they were found to cross the limits of host barrier into a different host, their real dangerousness and threat were implicit. Despite serious warnings from science of the impending pandemic, ${ }^{4-7}$ the world turns a deaf ear to them, and the consequences are devastating. The historical developments on our knowledge of these viruses have been documented, but the details and factuality are often missing. This article is an attempt to mend those gaps.

\section{The Misinformation Meme}

The word "misinformation" has also been very popular in media and scientific community in the wake of COVID-19. As a matter of fact, there has been a mountain of misinformation in the history of coronaviruses. This article will try to mitigate many of those. Just to point out specific example, Kahn and Mclntosh in their historical paper used an opening statement, "The history of human coronaviruses began in 1965 when Tyrrell and Bynoe found that they could passage a virus named B814." But the truth is it started in 1961 when B814 was collected from one boy. Cavanagh and Gelb Jr. asserted that one of the (quote) "milestones include the establishment of the etiology by Beach and Schalm in 1936." ${ }^{\prime 9}$ They are not aware of Leland David Bushnell and Carl Alfred Brandly who isolated and discovered the virus in 1933. Beach and Schalm, in the simplest sense, confirmed the Bushnell and
Brandly's discovered virus as a distinct species.

In the turmoil of the coronavirus infamy, it has become a fashion to misattributed Fred Robert Beaudette and Charles D. Hudson for the isolation and discovery of $\mathrm{IBV}^{10-15}$ (a gargantuan number of theses available in the web depositories are not worth mentioning) including in the standard etymological definition of coronavirus as adopted by the Centers for Disease Control and Prevention, U.S. Department of Health and Human Services. CDC website states: "The first coronavirus, avian infectious bronchitis virus, was discovered in 1937 by Fred Beaudette and Charles Hudson."16 Why the paper of Beaudette and Hudson (1937) ${ }^{17}$ is often cited as the discovery is really a perpetual misinformation meme; and it is not. It was the first report on the "cultivation" (laboratory culture) of the virus, and thus production the first culture sample. The Beaudette strain, to its own glory, became the first coronavirus to have its genome completely sequenced in $1987 .^{18}$

In some of the instances, the misunderstanding could have stemmed from Beaudette and Hudson frequent use of infectious bronchitis, in fact as early as in 1930, the details of which I have no access. But from their 1932 paper, it is obvious that they boldly use the name virus without actually knowing the pathogen. Their 1932 paper, for detail, is only 206word long in three paragraphs, which merely describes experimental infection of chicken from swab samples collected from the infected. ${ }^{19}$ There was no isolation of the virus or description of the symptoms, and most probably was a case of infectious laryngotracheitis, as the name was used overlappingly at the time. Beaudette more than anyone else was aware of this, as he remarked in 1937:

Infectious laryngotracheitis is said to be the correct name for this disease rather than infectious bronchitis... but... it is still not sufficiently inclusive. Moreover, the gasping symptom ordinarily accepted as typical of the disease is also a prominent symptom in infectious bronchitis (gasping disease, chick bronchitis). ${ }^{20}$

It is also evident he had since been dealing with infectious laryngotracheitis. Historical review support this. $^{21,22}$ Beaudette and Hudson can be rightfully credited as the first to identify virus as the pathogen of infectious laryngotracheitis.

\section{The jumbled-up chicken-and-egg story}

Coronaviruses seem to like America and it was from there that their story begins. Their infections were discovered by American veterinarians as an acute and highly contagious upper-respiratory tract disease of chickens, as Arthur Frederick Schalk and Merle C. Fawn at the North Dakota Agricultural College reported in $1931 .{ }^{23}$ The infection produced a 


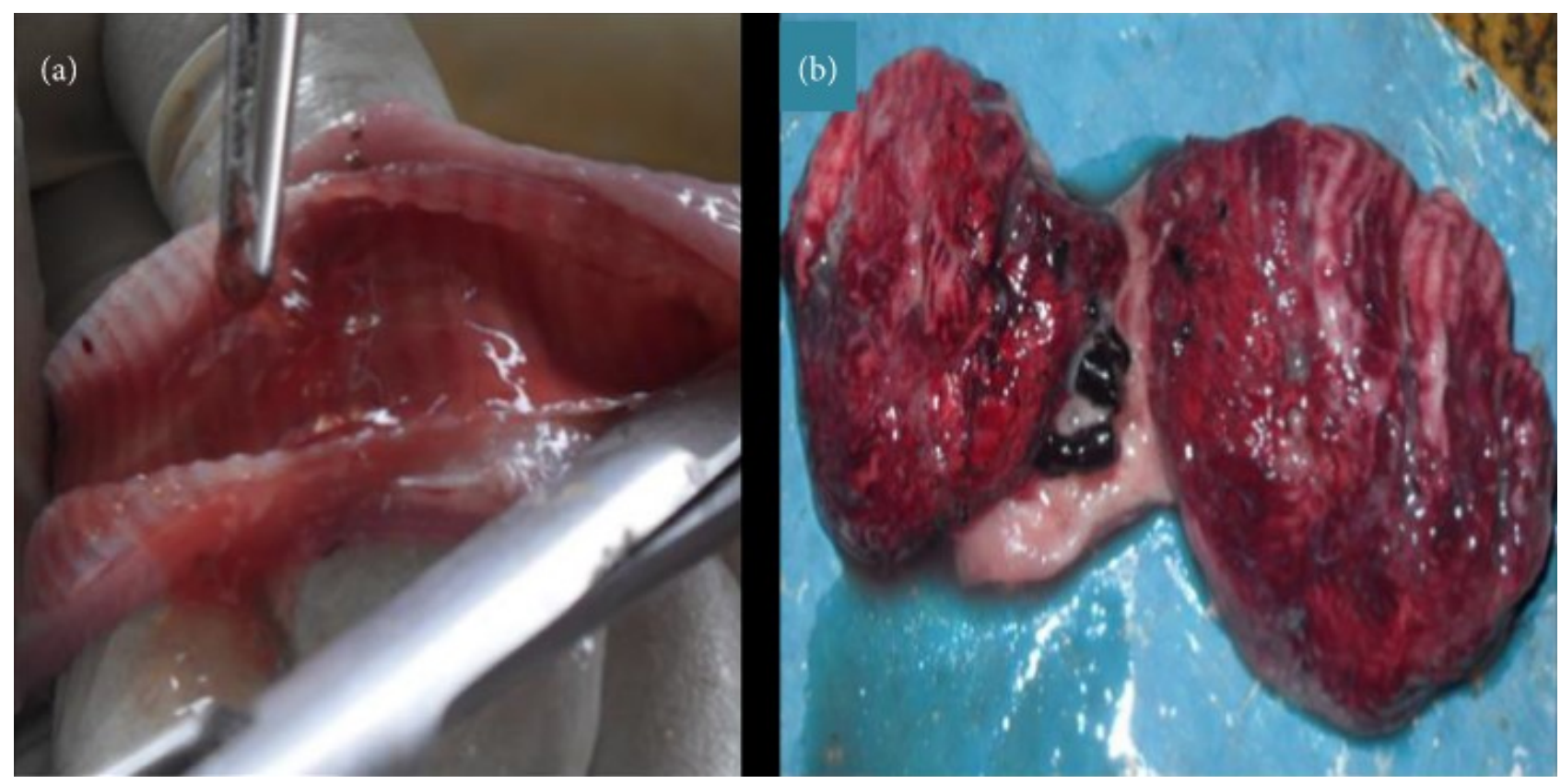

Figure 1 | Gross lesions observed on respiratory organs of chicken naturally infected with infectious bronchitis virus. A) Presence of mucoid secretion, congestion, and hyperaemia in the trachea. B) Lung consolidation. (Bande et al., 2016. https://doi.org/10.1155/2016/4621659)
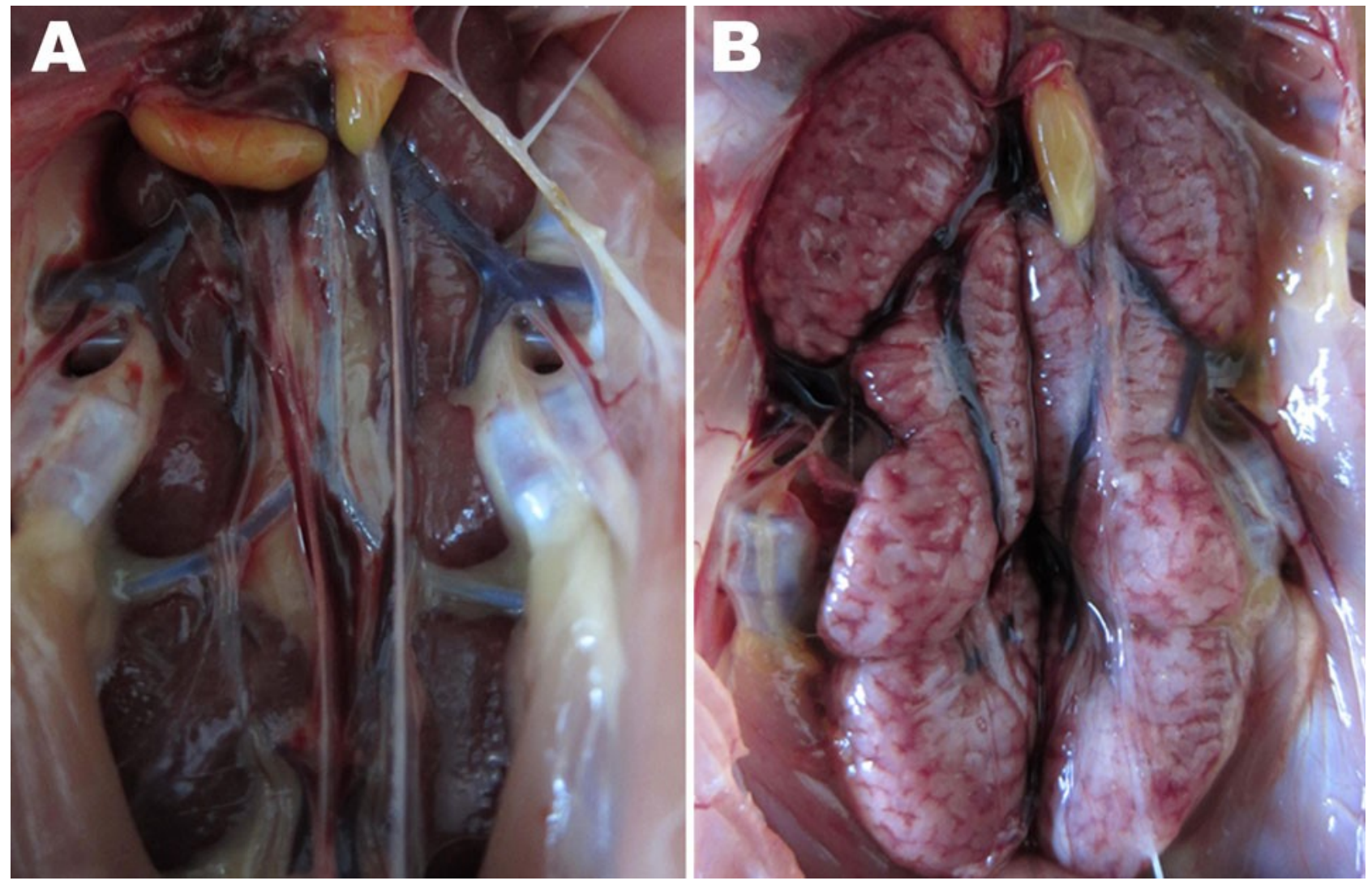

Figure 2 | A) Kidney tissue of a healthy chicken. B) Gross lesions in the kidney of chicken experimentally infected with infectious bronchitis virus YN strain at 7-day postinfection. (Feng et al., 2012. https://wwwnc.cdc.gov/eid/ article/18/12/12-0552-f4) 


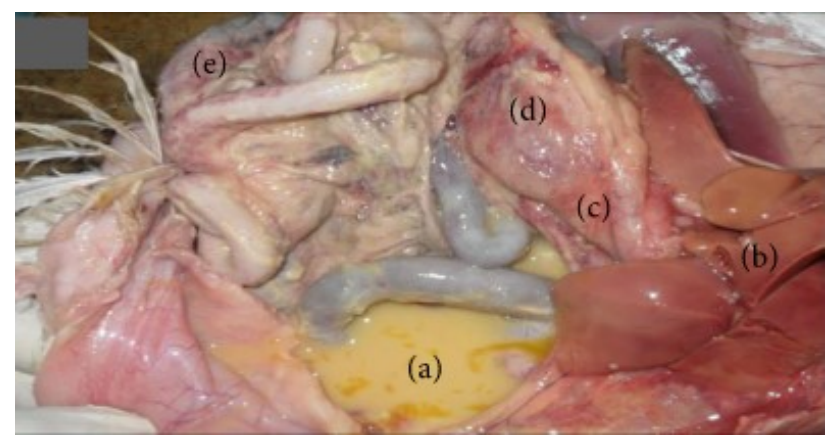

Figure 3 | Effect of IBV infection on different organs. A) Accumulation of egg yolk in abdominal cavity. B) Pale, friable liver. C) Multiple petechial haemorrhages on the serosal surfaces of proventriculus. D) Gizzard. E) Small intestine. (Bande et al., 2016. https://

doi.org/10.1155/2016/4621659)

never-before-seen symptoms of respiratory disorder in the annals of medicine (Figure 1-3). It was seen among 2-day-old to 3-week-old chickens, which developed severe shortness of breath and listlessness. The virulence of the infection was staggering, as mortality could reach $90 \%$. The most extraordinary facade of the new disease was an extremely infectious nature through direct contact or experimental transfer of the bronchial exudates o the infected to healthy chickens. ${ }^{24}$ Left with no further ability to analyse the disease, Schalk and Fawn gave the vaguest possible name, "an apparently new respiratory disease of baby chicks." ${ }^{23}$ Not knowing what kind of new disease it was or of the causative agent, they divested themselves from an eureka moment of the discovery of the coronavirus infection, for theirs was the first definitive description of the disease.

I say "definitive" because another chain of discoveries took a more circuitous route. Since 1923 it had been recorded that a new respiratory disease of chickens was rampaging in US, ${ }^{25,26}$ and Canada. ${ }^{27}$ It is not known for certain when the disease first appeared as it may well have dated back to 1920 in US. ${ }^{28}$ Thus, the original discovery is awfully obscured. The new disease was characterised by constant nasal discharge, often bloody, and gasping (dyspnoea). Ronald Gwatkin at the Veterinary Research Laboratory, Lethbridge, Canada, named it avian diphtheria in 1925. ${ }^{27}$ The American version was named infectious bronchitis by Jerry Raymond Beach of the University of California in $1926 .{ }^{29}$ It was established that infection was to be found in the exudates that accumulated in in the larynx and trachea of infected chickens. Then the name, avian laryngotracheitis, was adopted by Robert Graham, Frank Thorp Jr. and William Arthur James of the Illinois Agricultural Experiment Station in 1930. ${ }^{26,30-32}$ They reported that bacteria were their prime suspect as the pathogens, but a cohort of bacteria identified from infected chicken failed to identify the bacterium from known species, and simply concluded: "Morphologically, the pleomorphic micro -organism has coccoid, diplococcoid, ovoid, granular or beaded rod forms suggestive of the diphtheroid group." ${ }^{\prime 30}$

Their conviction to the diphtheria-type of disease was explicit. The complication, which later proved to be part of the solution, arose when they reported that there were actually two distinct but overlapping symptoms. But they were confused that while they were convinced that infectious bronchitis was nothing but laryngotracheitis, yet there was more than one serological type of the infection. In their initial study they found no distinction between the possible pathogens for the acute and chronic forms. ${ }^{31}$ But they subsequently discovered that that their accused bacterial could not be held responsible for the laryngotracheitis. ${ }^{32}$ After careful experimentation they came to a prudent explanation that the subacute form was caused by diphtheroid organisms while a filterable virus may be responsible for the acute form. ${ }^{26}$

Beach quickly solved one of the dilemmas. He identified the causative agent in 1930 as a filterable virus. $^{33}$ Virus are normally much smaller than bacteria and invisible under light microscope. Therefore, if a filter can filter out bacteria but the filtrate still contains a pathogen indicates that it must be a virus. Beach did exactly that and found that the virus infected not only the respiratory tract, but also spleen and livers, further revealing the pathogenic nature of the infection. $\mathrm{He}$ also introduced the names infectious laryngotracheitis and infectious bronchitis, but for the same disease. The next year he demonstrated the definitive experiment that it was virus alone that produced the symptoms. One important note he made was that the infection was extremely contagious so much so that off-target infection was hard to avoid. ${ }^{34}$

It was by then that three hypotheses were conceived as to the mode of transmission of the virus, such as spread by insects, passively carried by humans who handled chickens, or active transmission between chickens. ${ }^{35}$ Beach's experiment proved that it was chicken-to-chicken transmission. To settle the mixed-up names a special committee on poultry diseases of the American Veterinary Medical Association adopted "infectious laryngotracheitis" as the formal name of the disease in 1931. ${ }^{28}$ Beach had discovered what was later called infectious laryngotracheitis virus (ILV), and much later the scientific name was given by the authority on virus name the International Committee on Taxonomy of Viruses (ICTV) as Gallid herpesvirus 1 in 1995, and finally Gallid alphaherpesvirus 1 in 1998 (ICTV). The virus is not remotely related to coronaviruses and is classified under the order Herpesvirales. ${ }^{36}$ 
This digression to ILV biography is necessary because the coronaviruses emerged right in the middle of the confusion. Leland David Bushnell and Carl Alfred Brandly at the Kansas Agricultural Experiment Station, Manhattan, reported cases of "laryngotracheitis in chicks" in $1933 .{ }^{37}$ They had been investigating an outbreak since 1930 of what they called "gasping disease" among baby chickens in Kansas. The first report of the disease was in 1928. The disease spread very rapidly in America. The symptoms were distinct, although some overlapped with those of infectious laryngotracheitis: severe gasping that disabled eating, cold air made it more severe, short incubation (inoculated chicks developed the symptoms after one day), not only were the larynx and trachea affected, but also the bronchi and the lungs, rare nasal discharge, and swift death in about three to four days after initial symptoms. This disease was different by all measures. A battery of bacteriological tests ruled out the possibility of bacteria as the culprits, because the pathogenic lesions were clearly evident in the spleens, livers, and kidneys, where those bacteria would not normally survive. After eliminating all other possible factors including avitaminosis and protozoan infection, the only decision was that "the aetiology of the disease is a filter-passing virus." Their description of the isolation is worth reiterating as a number of writers have not understood that they discovered and isolated the virus for the first time, as they wrote:

In several experiments we have reproduced the disease in chicks by the intratracheal, subcutaneous and intraperitoneal injection of Berkefeld filtered material [used to filter out bacteria and other microbes but filter through viruses]. The chicks developed typical gasping symptoms after various periods of incubation, different groups of chicks first showing symptoms in six, seventeen, nineteen, etc., days after receiving the filtrate... The disease may also be transferred by means of filtrates of spleen, liver, and kidney tissues and by the transfer of bacteriologically sterile blood. ${ }^{37}$

Yet they ignored the distinctive features of the symptoms, preferring to remain in the safe haven of the existing wisdom than explore the unknown, concluding:

[It] seems certain that the "gasping" symptom is due to a filterable virus infection with severe involvement of the larynx, trachea, bronchi and lungs... The symptoms and lesions in the chicks are similar to those seen in so-called laryngotracheitis of adult birds and are probably due to the same agent. $^{37}$

It is interesting to note that Bushnell and Brandly used the term laryngotracheitis only, and not bronchitis, and made a critical mistake in attributing it to ILV, because unbeknown to them they had discovered infectious bronchitis virus (IBV), the first coronavirus ever known. Nor did they know that the virus they isolated was the causative agent of Schalk and Fawn's "new respiratory disease of baby chicks".

Bushnell and Brandly's was not a satisfying report, at least to judicious researcher such as Beach. The cloud of mysteries was cleared in 1936 when Beach and Oscar William Schalm reanalysed Bushnell and Brandly's report and experimentally confirmed that infectious laryngotracheitis and infectious bronchitis were distinct diseases, and also that the pathogenic viruses were also unique in each. Their experimental finding was succinct and conclusive:

1. It was found that chickens that recovered from an infection with one of the two strains of virus were refractory to further infection with either strain. It was also found that the sera from chickens that have recovered from an infection with one strain of the virus would neutralize virus of either strain. These results show the identity of the two strains of virus.

2. Chickens refractory to infection with this virus were shown to be susceptible to the virus of laryngotracheitis. Likewise, chickens refractory to the latter virus were susceptible to the former. These results demonstrate that the two viruses are distinct from one another. ${ }^{38}$

After all, ILV is a herpesvirus and IBV by contrast is a gammacoronavirus.

\section{What's in a name? a brain or a liver?}

By the 1950s it was established beyond doubt that IBV was a unique virus capable of causing a distinct disease. But related virus arrived on the sly. Since the early 1940s, the aetiological factors of brain disease (encephalomyelitis) in mice in which nerve cells were damaged spontaneously were actively investigated. Viruses, called Theiler's viruses (or Theiler's murine encephalomyelitis viruses, discovered by Max Theiler at the Rockefeller Foundation in New York in 1937), ${ }^{39}$ which are picornaviruses, were the main causative agents. But as two sides of a coin, the disease is two-faced, as a brain disease and liver infection.

On 14 August 1947, two laboratory mice (Schwenktker strain), aged 17-18 days old, suffered from flaccid paralysis at the Department of Bacteriology and Immunology, Harvard Medical School in Boston. Their symptoms were peculiar with no signs of illness or diarrhoea, characteristics of murine encephalomyelitis. Francis Sargent Cheevers, Joan B. Daniels, Alwin M. Pappenheimer and Orville T. Bailey investigated the case. Experiment inoculation of the brain perfusion broth of the two mice produced exactly similar symptoms in healthy mice. They were convinced that the symptoms were clearly the works of a new type of virus, which was notorious invasive as it could be isolated from all 
vital organs, the liver, spleen, lungs, and kidneys from infected mice. It could also infect rats and hamsters. ${ }^{40}$ In addition to the central nervous system, the virus also caused necrosis of liver, meaning hepatitis. ${ }^{41}$

The name behind the virus was disclosed nine years later and was not a well thought through. Pappenheimer reported that JHM was in honour of John Howard Mueller, their mentor, but with a slight tone of regret. He wrote: "In retrospect it seems a questionable compliment to have a malignant virus named after one." ${ }^{\prime 42}$ (Who would expect Peyton Rouse to have liked Rous sarcoma.) It would have been a sigh of relief when the official name by the ICTV became Murine coronavirus in 2009. ${ }^{43}$

In a separate chain of events, there was a frenzy of fatal infection among the breeding stock of mice (Parkes or $\mathrm{P}$ strain, to be precise) at the National Institute for Medical Research, Mill Hill, London, in the autumn of 1950. When Alan Watson Gledhill and Christopher Howard Andrewes investigated the outbreak, they found that the infected mice died of hepatitis (Figure 4). The astonishing observation was that although bacterial infections were evident, the pathological lesions were obviously due to virus, and bacteria were only seen as secondary infections. When they inoculated the liver extracts of infected $P$ mouse to a different mouse strain (VS), the new mice suffered the same lethal hepatitis. They arrived with a rather blunt conclusion: "The infective agent would be termed mouse hepatitis virus (MHV). ${ }^{\prime 44}$ It was not up to them for giving the lasting name, as the fate of scientific endeavour had more surprises in store.

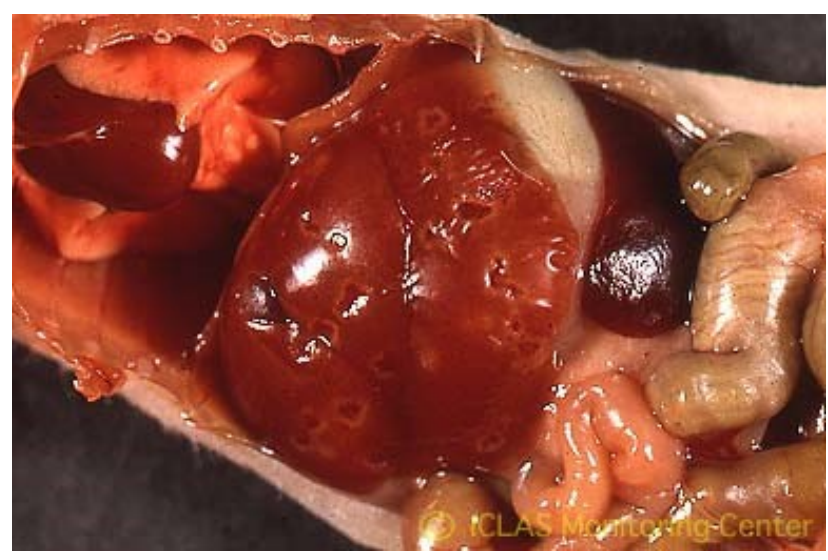

Figure 4 | Liver damage in mouse due to mouse hepatitis virus (MHV) infection. (https:// www.iclasmonic.jp/)

IBV, JHM and MHV had no apparent connection other than being very fatal viruses. Their target organs are so different, IBV for the respiratory tracts, JHM the brain and MHC the liver. There was a flicker of enlightenment in 1959 as John A. Morris at the National Institutes of Health, Bethesda, reported the discovery of a new murine virus, named $\mathrm{H} 747$, in Japan. What was astounding was that $\mathrm{H} 747$ was antigenically similar to JHM and MHV. For brevity Morris even gave a collective name for the three viruses as hepatoencephalitis group of murine viruses. ${ }^{45}$

As to the case of the relationship between IBV and murine viruses, pathology and immunology had nothing more to offer. Then, the development of has unprecedented surprise in store. The faces of IBV were first shown by Reginald L. Reagan, Jean E. Hauser, Mary G. Lillie, and Arthur H. Craige Jr. of the University of Maryland in $1948 .{ }^{46}$ The first electron microscopic images were far from looking in the mirror and nothing more than fuzzy spherical blobs such that it was practically impossible to make out a coherent picture of the virus amidst the infected tissues. ${ }^{47,48}$ They showed no particular distinction from those of other viruses. By the late 1950s, the blurry images started to take form of clear spherical structures. In fact, a central hollow space surrounded by a thick cover justified the description "doughnutlike structures". ${ }^{49}$

As the resolutions of electron microscopy (EM) were improved, the images could reveal the structural details by the early 1960s. The first definitive high-resolution images of IBV by $D$. M. Berry at the Glaxo Laboratories, Middlesex, UK, and collaborators at the University of Cambridge, in 1964 began to reveal the clear structural distinction from other viruses. The thick cover was not just thick. The corona was laid bare as surface projections, and for the first time, the most unique structures, the spikes, were described:

Most but not all of the particles had projections from their surfaces. These "spikes" were often seen over part of the surface only and were less densely packed than those seen in influenza viruses. They varied considerably in shape. Commonly they appeared to be attached to the virus by a very narrow neck and to thicken towards their distal ends, sometimes forming a bulbous mass 90-110 $\AA$ in diameter. ${ }^{50}$

The EM image of MHV J. F. David-Ferreira and R. A. Manaker from the National Cancer Institute, Bethesda, in 1965 also showed discrete structural details. Above all, the presence of halo was clear as daylight, and they used "spicules" for the description. ${ }^{51}$ In comparison, the two viruses not just showed uncanny resemblance but that they were nothing but of the same kind - the devil is merely in the detail.

\section{What is man, that thou art mindful of him?}

The story of human coronaviruses starts and interweaves with that of common cold, the most 


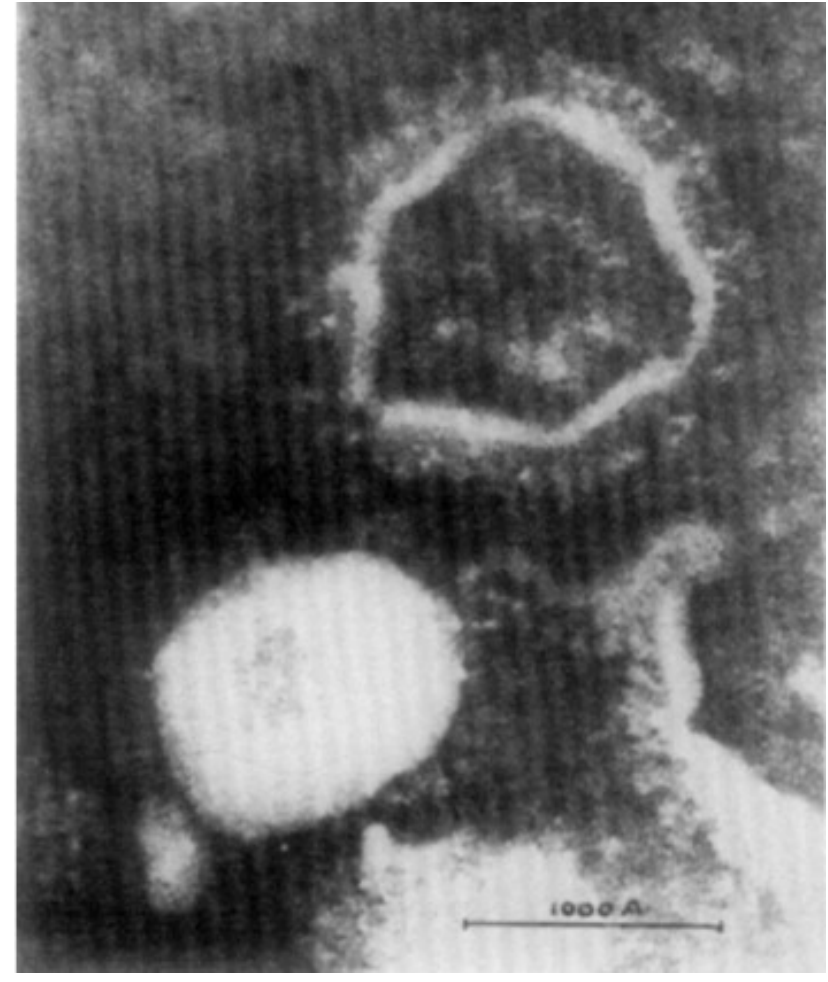

Figure $\mathbf{5}$ | The first definitive transmission electron microscopic image of coronavirus, in this case infectious bronchitis virus, from Berry et al. (1964). ${ }^{50}$ Two viruses are visible. The upper one shows the distinctive corona, which they named "spikes".

common disease ever. This is because in humans, coronaviruses are among more than 200 types of viruses that cause common cold, with only a slight difference. In spite of its antiquity and universality, common cold as a scientific enterprise came very late in the annals of science. One should understand that the constraint lies in the fact that the causative agents are exceedingly miniscule and cannot be seen even with a light microscope, which make it a perfect miasma.

The first scientific challenge was taken up by a German physician Walther Kruse, working as professor of hygiene in Leipzig University, Germany. He performed two ingenious experiments in January and June of 1914. Using samples prepared from nasal discharge of his assistant who was suffering from cold, he was able to induce the infection in healthy volunteers. It was evident that common cold was not a mere miasma, but due to an imperceptible organism. Back then viruses were not that famous, so that he was tempted to identify, and erroneously too, the pathogen as Aphanozoa coryzae. ${ }^{52}$ Clearly, he had some sort of protozoan in mind. He could have done better had not the First World War break out immediately after.

Begrudgingly, the common cold had to receive an undivided attention only at the end of the next great war, the Second World War. It started with the establishment of the Common Cold Research Unit (CCRU) at Salisbury in 1946 by the British Medical Research Council and the Ministry of Health, UK. ${ }^{53}$ Andrewes, who we met earlier in MHV discovery, became its first director. Within a decade, he and his collaborators discovered that common colds are caused by a consortium of viruses including influenza viruses, parainfluenza viruses and rhinoviruses. $^{54,55}$ The sheer number is enough to dissuade any sane researcher looking for a cure or vaccine.

It was time for a fresh mind in the form of David Arthur John Tyrrell to take over the daunting task. Tyrrell joined the CCRU in 1957 succeeded Andrewes as the director in 1962. His early breakthrough was the development of culture methods by which he could conveniently categorise common cold viruses into two distinct groups, namely those that can be maintained both in human-embryo-kidney cell culture and monkey-embryo-kidney cell culture, called the $M$ strain, and those that can be maintained only in human-embryo-kidney cell culture, called the $\mathrm{H}$ strain. ${ }^{56,57}$ Their initial studies revealed that all common cold viruses belong to either one. Using the contradistinction method, a very peculiar cold virus emerged. During 1960 to 1961 his team examined boys at boarding schools who were having common cold, collected samples (throat and nasal swabs). To their utter astonishment some samples could not be cultured by their conventional methods, implying that the viruses could be neither $\mathrm{M}$ nor $\mathrm{H}$ strains. ${ }^{58}$ One sample in particular, designated B814, collected from one boy on 17 February 1961, was exceedingly contagious when they inoculated to healthy volunteers. Due to its extraordinary property, they were baffled over whether the cold agent was a virus or a bacterium, and had no foggiest idea that they had a human coronavirus in their hands.

A battery of experiments for three years made them came to the conclusion in 1965 that the cold agent in B814 was a different virus as it could pass through bacteria filters, be inactivated by ether, and could induce the symptoms in volunteers who were given antibiotics. The sensitivity to ether further implied that the virus did not belong to any known virus groups at the time, such as adenovirus, enterovirus, or rhinovirus. Analysis of the clinical symptoms also indicated that the cold due to the new virus was not as common as common colds. The fevers were more severe, more frequent, and had short incubation period compared to those of other common colds. Finally, it could be grown in humanembryo-trachea epithelial cell culture. ${ }^{59}$

On the other side of the Atlantic, Dorothy Hamre and John J. Procknow at the Department of Medicine, University of Chicago, had been investigating upper respiratory tract infection prevalent among medical students. Six of their 
samples collected in 1962 were tested negative for all known viruses. The samples, labelled 229E, could be cultured in secondary human kidney tissue but not in monkey-embryo-kidney cell, and were very infectious. They reported it as "a new virus isolated from the human respiratory tract" in $1966 .{ }^{60}$ With David A. Kindig and Judith Mann, Hamre studied the nature of $229 \mathrm{E}$ finding it that it was ether-sensitive ribonucleic acid virus. They made scanning electron microscopy of the stages of development of the virus. $^{61}$

Upon this new discovery, Tyrrell quickly had a light-bulb moment - all viruses of the usual suspects in the new disease had common features, if not exact similarity. With the help of June Dalziel Almeida at the St Thomas's Hospital Medical School in London, he performed comparative electron microscopy of B814 and 229E. He would not have been disappointed by the findings that the two viruses were structurally indistinguishable from one another, and moreover, from IBV They could not help but to conclude:

Probably the most interesting finding from these experiments was that two human respiratory viruses, $229 \mathrm{E}$ and B814. are morphologically identical with avian infectious bronchitis. Their biological properties, as far as they are known, are consistent with this. Both the human viruses are ether sensitive as is avian infectious bronchitis 229 $\mathrm{E}$, have a similar size by filtration and multiply in the presence of an inhibitor of DNA synthesis. ${ }^{62}$

Structural similarity aside, B814 and 229E were both rather quite harmless viruses and caused common colds as those of rhinoviruses. The only differences were that the colds due to the new viruses had longer incubation period of 3.3 days (2-5 days) compared to 2.1 days for rhinoviruses, but shorter symptomatic duration (6.5 days in contrast to 9.5 days for rhinoviruses, and disgusting with more snot. ${ }^{63}$

To add to the element of surprise, their subsequent comparison of these viruses with MHV uncovered the same resemblance. ${ }^{64}$ Stimulated by such works, Kenneth Mclntosh and colleagues at the National Institute of Health, Bethesda, reexamined samples they collected during 1965 to 1966 from patients with respiratory disease. Six of their samples (which they designated OC, for organ culture, with serial number) showed similarities to B814 and 229E, and structural resemblance to IBV under electron microscopy. ${ }^{65,66}$ Until the news of Tyrrell and Almeida's, Mclntosh's impression was that "It was just the common cold. Not a big deal." But Mclntosh's team soon realised that it was a deal of a lifetime. They made their case clear, asserting, "These viruses possessed a similar and characteristic morphology; because of their resemblance to IBV, we have tentatively designated them 'IBV-like' viruses." ${ }^{67}$ And for the first time, they even demonstrated that their virus could induce murine hepatitis. ${ }^{66}$ The similarities could not be a mere coincidence, twins or triplets are not identical for no reasons; and the only logical conclusion was that they were of the same kind.

The misty coast subsided, the horizon became visibly clear. All these new viruses have been one and only one type which had been living a triple life, in chickens, mice and humans - a trinity of viruses, one might be tempted to say. It was time for a fresh baptism. It was no longer reasonable to play doubting Thomas. A new collective name was needed. Tyrrell thought of "influenza-like viruses", but then conceded that it sounded feeble and lacked novelty. A star-studded crew of the new virology submitted in Nature in 1968 that the viruses should be called coronaviruses, as the journal reported:

Particles [of IBV] are more or less rounded in profile; although there is a certain amount of polymorphism, there is also a characteristic "fringe" of projections $200 \AA$ long, which are rounded or petal shaped, rather than sharp or pointed, as in the myxoviruses. This appearance, recalling the solar corona, is shared by mouse hepatitis virus and several viruses recently recovered from man, namely strain B814, 229E and several others...

In the opinion of the eight virologists these viruses are members of a previously unrecognized group which they suggest should be called the coronaviruses, to recall the characteristic appearance by which these viruses are identified in the electron microscope. ${ }^{68}$

The list of start virologist includes Almeida, Berry, C.H. Cunningham, Hamre, M.S. Hofstad, L. Mallucci, McIntosh and Tyrrell.

The newly established (in 1966) authority called the International Committee for the Nomenclature of Viruses (ICNV, later renamed ICTV in 1975) lost no time in endorsing the new name the same year. ICNV formally authorised the genus name Coronavirus in 1971, and the family name Coronaviridae in $1975 .{ }^{69}$ Thus, the name coronavirus became legitimate and binding for eternity.

But their versality was underestimated. It was not long before new coronaviruses were discovered in pigs, rats, dogs, and later in bats, bulbuls, beluga whales, foxes, and hedgehogs. To add to the distress they already caused, the bat coronaviruses have developed an inordinate fondness for humans. ${ }^{2-8}$ Another report in the British Medical Journal on the new name in 1969 opens with a rather sentimental and stimulating statement:

One of the fascinations of scientific work is when patiently accumulated facts suddenly "fit together" in a new and interesting way. This has recently occurred with three apparently unrelated viruses which, known to cause diseases of man and animals, have now been shown to belong to one 
large biological group. ${ }^{70}$ stated:

The reason for the new name was more explicitly

Because of all these findings it has now been suggested that, in spite of their different origins and pathogenicity, these viruses belong to a single biological group. The group name suggested is coronaviruses-to recall the crownlike outline of some particles in electron micrographs, and their resemblance to the solar corona. The name is much less of a mouthful than avian-infectious-bronchitislike viruses. ${ }^{70}$

There is a trace of irony to recapitulate that people who gave prodigious names as Severe acute respiratory syndrome-related coronavirus (with the abbreviation itself still quite mouthful, SARS-CoV-2) paid lip service to the judiciousness of pioneer scientists and the very history. The report ended with a prophetic remark: Clearly a new chapter has been started in the story of the causes of the common cold-and it is headed "coronaviruses". ${ }^{70}$ It would have been a spot-on prescience had they appended "with the new greatest pandemic."

\section{Acknowledgement}

Access-restricted information were obtained through N-LIST INFLIBNET, Ministry of Human Resource Development, Government of India, and The Wikipedia Library, Wikimedia Foundation.

\section{References}

1. Gorbalenya, A.E., Baker, S.C., Baric, R.S., de Groot, R.J., Drosten, C., Gulyaeva, A.A., Haagmans, B.L., Lauber, C., Leontovich, A.M., Neuman, B.W., Penzar, D., Perlman, S., Poon, L.L.M., Samborskiy, D.V., Sidorov, I.A., Sola, I., Ziebuhr, J. (2020). The species Severe acute respiratory syndrome-related coronavirus: classifying 2019-nCoV and naming it SARS-CoV-2. Nature Microbiology, 5, 536-544.

2. Cui, J., Li, F., Shi, Z.L. (2019). Origin and evolution of pathogenic coronaviruses. Nature Reviews Microbiology, 17(3), 181-192.

3. Chen, Y., Liu, Q., Guo, D. (2020). Emerging coronaviruses: genome structure, replication, and pathogenesis. Journal of Medical Virology, 92(4), 418 -423 .

4. Li, W., Shi, Z., Yu, M., Ren, W., Smith, C., Epstein, J.H., Wang, H., Crameri, G., Hu, Z., Zhang, H., Zhang, J. (2005). Bats are natural reservoirs of SARS-like coronaviruses. Science, 310(5748), 676679.

5. Fan, Y., Zhao, K., Shi, Z.L., Zhou, P. (2019). Bat coronaviruses in China. Viruses, 11(3), 210(1-14).

6. Menachery, V.D., Yount Jr., B.L., Debbink, K., Agnihothram, S., Gralinski, L.E., Plante, J.A., Graham, R.L., Scobey, T., Ge, X.Y., Donaldson, E.F., Randell, S.H. (2015). A SARS-like cluster of circulating bat coronaviruses shows potential for human emergence. Nature Medicine, 21(12),15081513.

7. Menachery, V.D., Yount, B.L., Sims, A.C., Debbink, K., Agnihothram, S.S., Gralinski, L.E., Graham, R.L., Scobey, T., Plante, J.A., Royal, S.R., Swanstrom, J. (2016). SARS-like WIV1-CoV poised for human emergence. Proceedings of the National Academy of Sciences USA, 113(11), 3048-3053.

8. Kahn, J.S., McIntosh, K. (2005). History and recent advances in coronavirus discovery. The Pediatric Infectious Disease Journal, 24(11), S223-S227.

9. Cavanagh, D., Geld Jr., J (2008). Infectious bronchitis. In: Saif, Y.M., ed. Diseases of Poultry (12 edition). Blackwell Publishing, Iowa, US, p. 117.

10. Beniac, D.R., Booth, T. F. (2010). Structural molecular insights into SARS coronavirus cellular attachment, entry and morphogenesis. In: Lal, S., ed., Molecular Biology of the SARS-Coronavirus. Springer, Berlin, Heidelberg, pp. 31-43.

11. Promkuntod, N., Van Eijndhoven, R. E. W., De Vrieze, G., Gröne, A., Verheije, M. H. (2014). Mapping of the receptor-binding domain and amino acids critical for attachment in the spike protein of avian coronavirus infectious bronchitis virus. Virology, 448, 26-32.

12. Wang, W., Lin, X.D., Guo, W.P., Zhou, R.H., Wang, M.R., Wang, C.Q., Ge, S., Mei, S.H., Li, M.H., Shi, M., Holmes, E. C. (2015). Discovery, diversity and evolution of novel coronaviruses sampled from rodents in China. Virology, 474, 1927.

13. Torres, J., Surya, W., Li, Y., Liu, D.X. (2015). Protein-protein interactions of viroporins in coronaviruses and paramyxoviruses: new targets for antivirals? Viruses, 7(6), 2858-2883.

14. Kasmi, Y., Khataby, K., Souiri, A., Ennaji, M. M. (2020). Coronaviridae: 100,000 years of emergence and reemergence. In: Ennaji, M.M., ed. Emerging and Reemerging Viral Pathogens. Academic Press. pp. 127-149

15. Ludwig, S., Zarbock, A. (2020). Coronaviruses and SARS-CoV-2: A brief overview. Anesthesia and Analgesia, 131(1), 93-96.

16. Henry, R. (2020). Etymologia: Coronavirus. Emerging Infectious Diseases, 26(5), 1027. 
17. Beaudette, F.R., Hudson, B.D. (1937). Cultivation of the virus of infectious bronchitis. Journal of the American Veterinary Medical Association, 90, 51-60.

18. Boursnell, M. E. G., Brown, T. D. K., Foulds, I. J., Green, P. F., Tomley, F. M., Binns, M. M. (1987). Completion of the sequence of the genome of the coronavirus avian infectious bronchitis virus. Journal of General Virology, 68(1), 57-77.

19. Hudson, C. B., Beaudette, F. R. (1932). Infection of the cloaca with the virus of infectious bronchitis. Science, 76(1958), 34-34.

20. Beaudette, F.R. (1937). Infectious laryngotracheitis. Poultry Science, 16(2), 103-105.

21. Weaver, C. H. (1942). Infectious laryngotracheitis: Its diagnosis and control. Canadian Journal of Comparative Medicine and Veterinary Science, 6(4), 107-115.

22. Jordan, F. T. W. (1966). A review of the literature on infectious laryngotracheitis (ILT). Avian Diseases, 10(1), 1-26.

23. Schalk, A.F., Hawn, M.C. (1931). An apparently new respiratory disease of baby chicks. Journal of the American Veterinary Medical Association, 78(3), 413-422.

24. Fabricant, J. (1998). The early history of infectious bronchitis. Avian Diseases, 42(4), 648-50.

25. Hinshaw, W.R. (1924). Studies in poultry diseases found in poultry feeding stations. National Poultry Butter and Egg Bulletin, 9, 3-6.

26. Graham, R., Thorp, F., James, W.A. (1930). A note on avian laryngotracheitis. Journal of the American Veterinary Medical Association, 77, 587-794.

27. Gwatkin, R. 1925. Some notes on avian diphtheria. Ontario Veterinary College Report for 1924, 1925, 5461.

28. Cover, M.S. (1996). The early history of infectious laryngotracheitis. Avian Diseases, 40(3), 494-500.

29. Beach, J.R. (1926). Infectious bronchitis of fowls. Journal of the American Veterinary Medical Association, 68, 570-580.

30. Graham, R., Thorp, F., James, W.A. (1930). Pleomorphic micro-organism associated with acute infectious avian laryngotracheitis. The Journal of Infectious Diseases, 47(2), 83-86.

31. Graham, R., Thorp, F. and James, W.A. (1930). Subacute or chronic infectious avian laryngotracheitis. The Journal of Infectious Diseases, 47(2), 87-91.

32. Graham, R., Thorp Jr, F. and James, W.A. (1930). The pathogenicity of a pleomorphic microorganism isolated from avian laryngotracheitis. The Journal of Infectious Diseases, 47(4), 340-344.

33. Beach, J.R. (1930). The virus of laryngotracheitis of fowls. Science, 72(1877), 633-634.

34. Beach, J.R. (1931). A filtrable virus, the cause of infectious laryngotracheitis of chickens. The Journal of Experimental Medicine, 54(6), 809-816.

35. Komarov, A. and Beaudette, F.R. (1932). Carriers of infectious bronchitis. Poultry Science, 11(6), 335338.

36. ICTV. ICTV Taxonomy history: Gallid herpesvirus 1. International Committee on Taxonomy of Viruses. https://talk.ictvonline.org/taxonomy/p/taxonomyhistory?

taxnode_id=19951033\&src=NCBI\&ictv_id=1995103 3

37. Bushnell, L.D., Brandly, C.A. (1933). Laryngotracheitis in chicks. Poultry Science, 12(1), 55-60.

38. Beach, J.R., Schalm, O.W. (1936). A filterable virus, distinct from that of laryngotracheitis, the cause of a respiratory disease of chicks. Poultry Science, 15 (3), 199-206.

39. Theiler, M. (1937). Spontaneous encephalomyelitis of mice, a new virus disease. The Journal of Experimental Medicine, 65(5), 705-719.

40. Cheever, F.S., Daniels, J.B., Pappenheimer, A.M., Bailey, O.T. (1949). A murine virus (JHM) causing disseminated encephalomyelitis with extensive destruction of myelin: I. Isolation and biological properties of the virus. The Journal of Experimental Medicine, 90(3), 181-194.

41. Bailey, O.T., Pappenheimer, A.M., Cheever, F.S., Daniels, J.B. (1949). A murine virus (JHM) causing disseminated encephalomyelitis with extensive destruction of myelin: II. Pathology. The Journal of Experimental Medicine, 90(3), 195-212.

42. Pappenheimer, A.M. (1958). Pathology of infection with the JHM virus. Journal of the National Cancer Institute, 20(5), 879-891.

43. ICTV. ICTV Taxonomy history: Murine coronavirus. International Committee on Taxonomy of Viruses. https:/talk.ictvonline.org/taxonomy/p/taxonomyhistory?taxnode_id=20140897

44. Gledhill, A.W., Andrewes, C.H. (1951). A hepatitis virus of mice. British Journal of Experimental Pathology, 32(6), 559.

45. Morris, J.A. (1959). A new member of hepatoencephalitis group of murine viruses. Proceedings of the Society for Experimental Biology and Medicine, 100(4), 875-877. 
46. Reagan, R.L., Hauser, J.E., Lillie, M.G., Craige Jr., A.H. (1948). Electron micrograph of the virus of infectious bronchitis of chickens. The Cornell Veterinarian, 38(2), 190-190.

47. Reagan, R.L., Brueckner, A.L., Delaplane, J.P. (1950). Morphological observations by electron microscopy of the viruses of infectious bronchitis of chickens and the chronic respiratory disease of turkeys. The Cornell Veterinarian, 40(4), 384-386.

48. Reagan, R.L., Brueckner, A.L. (1952). Electron microscope studies of four strains of infectious bronchitis virus. American Journal of Veterinary Research, 13(48), 417-418.

49. Domermuth, C.H., Edwards, O.F. (1957). An electron microscope study of chorioallantoic membrane infected with the virus of avian infectious bronchitis. The Journal of Infectious Diseases, 1, 74-81.

50. Berry, D.M., Cruickshank, J.G., Chu, H.P., Wells, R.J. (1964). The structure of infectious bronchitis virus. Virology, 23(3), 403-407.

51. David-Ferreira, J.F., Manaker, R.A. (1965). An electron microscope study of the development of a mouse hepatitis virus in tissue culture cells. The Journal of Cell Biology, 24(1), 57-78.

52. Kruse, W.V. (1914). Die Erreger von Husten und Schnupfen [The causative agents of coughing and sniffling]. Münchener Medizinische Wochenschrift, 61, 1547 .

53. Anon. (1946). Research into the common cold. Nature, 157, 726-727.

54. Andrewes, C.H. (1958). A decade with the common cold. Bulletin of the Johns Hopkins Hospital, 103(1), 1-7.

55. Andrewes, C.H. and Worthington, G. (1959). Some new or little-known respiratory viruses. Bulletin of the World Health Organization, 20(2-3), 435-443.

56. Tyrrell, D.A., Bynoe, M.L. (1961). Some further virus isolations from common colds. The British Medical Journal, 1(5223), 393-397.

57. Tyrrell, D.A., Bynoe, M.L. (1965). Cultivation of a novel type of common-cold virus in organ cultures. The British Medical Journal, 1(5448),14671469.

58. Kendall, E.J., Bynoe, M.L., Tyrrell, D.A. (1962). Virus isolations from common colds occurring in a residential school. The British Medical Journal, 2 (5297), 82-86.

59. Tyrrell, D.A., Bynoe, M.L. (1965). Cultivation of a novel type of common-cold virus in organ cultures. The British Medical Journal, 1(5448), 1467-
1469.

60. Hamre, D., Procknow, J.J. (1966). A new virus isolated from the human respiratory tract. Proceedings of the Society for Experimental Biology and Medicine, 121(1), 190-193.

61. Hamre, D., Kindig, D.A., Mann, J. (1967). Growth and intracellular development of a new respiratory virus. Journal of Virology, 1(4), 810-816.

62. Almeida, J. D., Tyrrell, D. A. (1967). The morphology of three previously uncharacterized human respiratory viruses that grow in organ culture. Journal of General Virology, 1(2), 175-178.

63. Bradburne, A.F., Bynoe, M.L., Tyrrell, D.A. (1967). Effects of a "new" human respiratory virus in volunteers. British Medical Journal, 3(5568), 767769 .

64. Tyrrell, D.A., Almeida, J.D. (1967). Direct electronmicroscopy of organ cultures for the detection and characterization of viruses. Archiv für die Gesamte Virusforschung, 22(3-4), 417-425.

65. McIntosh, K., Dees, J.H., Becker, W.B., Kapikian, A.Z, Chanock, R.M. (1967). Recovery in tracheal organ cultures of novel viruses from patients with respiratory disease. Proceedings of the National Academy of Sciences USA, 57(4), 933-940.

66. Becker, W.B., McIntosh, K., Dees, J.H., Chanock, R.M. (1967). Morphogenesis of avian infectious bronchitis virus and a related human virus (strain 229E). Journal of Virology, 1(5), 1019-1027.

67. McIntosh, K., Becker, W.B., Chanock, R.M. (1967). Growth in suckling-mouse brain of "IBV-like" viruses from patients with upper respiratory tract disease. Proceedings of the National Academy of Sciences USA, 58(6), 2268-2273.

68. Almeida, J.D., Berry, D.M., Cunningham, C.H., Hamre, D., Hofstad, M.S., Mallucci, L., McIntosh, K., Tyrrell, D.A. (1968). Virology: Coronaviruses. Nature, 220(5168), 650.

69. Fenner, F., Maurin, J. (1976). The classification and nomenclature of viruses. Archives of Virology, 51(12), 141-149.

70. Anon. (1969). Viruses of birds, mice, and men. The British Medical Journal, 1(5645), 658-659. 